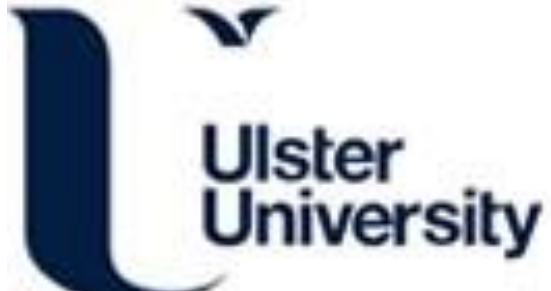

\section{Body-centric antenna positioning effects for off-body UWB communications in a contemporary learning environment}

Catherwood, P., \& Scanlon, W. (2014). Body-centric antenna positioning effects for off-body UWB

communications in a contemporary learning environment. In Unknown Host Publication (pp. 1571-1574). European Conference on Antennas and Propagation. https://doi.org/10.1109/EuCAP.2014.6902084

Link to publication record in Ulster University Research Portal

\section{Published in:}

Unknown Host Publication

Publication Status:

Published (in print/issue): 11/04/2014

DOI:

10.1109/EuCAP.2014.6902084

\section{Document Version}

Author Accepted version

\section{General rights}

Copyright for the publications made accessible via Ulster University's Research Portal is retained by the author(s) and / or other copyright owners and it is a condition of accessing these publications that users recognise and abide by the legal requirements associated with these rights.

\section{Take down policy}

The Research Portal is Ulster University's institutional repository that provides access to Ulster's research outputs. Every effort has been made to ensure that content in the Research Portal does not infringe any person's rights, or applicable UK laws. If you discover content in the Research Portal that you believe breaches copyright or violates any law, please contact pure-support@ulster.ac.uk. 


\title{
BODY-CENTRIC ANTENNA POSITIONING EFFECTS FOR OFF-BODY UWB COMMUNICATIONS IN A CONTEMPORARY LEARNING ENVIRONMENT
}

\author{
P. A. Catherwood and W. G. Scanlon \\ Institute of Electronics, Communications and Information Technology, The Queen's University of Belfast \\ Queen’s Road, Belfast, BT3 9DT, UK. E-mail: p.catherwood@qub.ac.uk,w.scanlon@qub.ac.uk
}

\begin{abstract}
The propagation of UWB signals for body-centric communications within a modern classroom/conference room environment was investigated. Presented results demonstrate that the body-antenna mounting position has a marked impact on the received power levels and positioning the antenna on the chest as opposed to the shoulder or wrist creates more extreme values in receive power, mean excess delay and rms delay spread. Additionally, the best fit models for each scenario are presented and highlight the difference between the chest and other compared antenna locations. The work concluded that the chest is a poor choice of mounting position for the antenna due to significant body shadowing effects, with the wrist or shoulder considered better options for UWB systems.
\end{abstract}

Index Terms - antenna, propagation, UWB, body-centric.

\section{INTRODUCTION}

As digital technology permeates learning and business environments the need to understand and model the wireless communication channels which many of these technology systems may utilize is essential. The expanding adaption of digital technology within the emerging learning environment is well documented, offering blended personal interactive learning experiences, real-time collaboration with peers, dynamic high-definition multimedia participation and genuine inclusion of those with learning disabilities [1-3].

Ubiquitous learning technology can support dyslexic, visually impaired and foreign language learners [4-6] and immersive technologies such as high definition Augmented Reality (AR) can provide students with an inclusive and engaging experience [7]. The same is also true for the business community, giving architects, engineers, artists and clinicians a futuristic method to share vision and creativity in conference/meeting room environments. It is envisaged that such technology will be coupled with wireless personal area networks (PAN) which is an increasing trend in user-centric communications [8]. This paper reports on an analysis of potential antenna-body locations for a mobile user for an offbody UWB indoor wireless communications channel. Mounting positions selected were the chest, shoulder and wrist to reflect popular antenna locations, such as those which use lanyards, armbands/epaulettes and wrist watches.

\section{EXPERIMENTAL ARRANGEMENTS}

The wearable channel characterization system consisted of an UWB source (3.1-6.0 GHz) positioned in a holster on the rear of the waist, feeding a body-mounted vertically-polarized UWB transmit antenna (launch power of $-12 \mathrm{dBm}$ ) via an RFover-fiber link (1550 nm 9/125 single mode, $0 \mathrm{~dB}$ gain). The fiber feed arrangement was specifically developed to ensure distortions of power and time dispersion characteristics associated with the use of co-axial cable feeds were kept to a minimum [9]. A frequency domain technique was employed throughout to de-convolve the measurement system from the received signal to leave only the propagation channel.

The measurement environment was a $40 \mathrm{~m}^{2}$ modern classroom with computer terminals around the walls and tables in the center. Tests were conducted for the transmit antenna placed on three specific body locations; the sternum of the chest, the deltoid muscle of the left shoulder and on the left wrist. Test configurations were either with the transmitting body-antenna approaching the receiver (which was wall mounted at a height of $2 \mathrm{~m}$, representative of an access point) or the transmitting body-antenna retreating from the receiver (Fig. 1). The approaching journey started $6 \mathrm{~m}$ from the receiver and ended $2 \mathrm{~m}$ from the receiver; the retreating journey retraced this path in the opposite direction.

\section{KEY RESULTS AND DISCUSSION}

\section{A. Received power statistics}

Results showed that the antenna position on the body had a marked impact of the received power levels (Table 1). For the trials where the transmitting antenna was positioned on the chest and approaching the receiver in line of sight (LOS) the mean power was higher than the isolated antenna due to the directivity of the body. The chest-positioned arrangement for the user retreating from the receiver (non- line of sight (NLOS)) conversely had the lowest received power due to the effects of body shadowing. This is reflected in previous UWB Personal Area Network research [10, 11].

Whether the antennas on the shoulder and the wrist are LOS or NLOS is dependent on the physical orientation of the transmit antenna with respect to the receiver and varies as the body moves, thus for both the approaching and retreating journeys the antennas are neither solely LOS nor NLOS. Instead the off-body link typically experiences both LOS and body shadowing as the body moves naturally in both directions. Indeed the received power time series for the shoulder and wrist (not shown for brevity) show cyclic fluctuations as the arms swing and the upper torso rotates. The chest had the largest difference in average received power levels between the two journey directions and also had the largest deviations from the isolated average power levels. The shoulder and wrist mean levels were marginally higher than isolated antenna levels; this is attributable to the strong LOS component available for this body-antenna location and presence of the body which acts as another source for multipath propagation through reflection and scattering. 


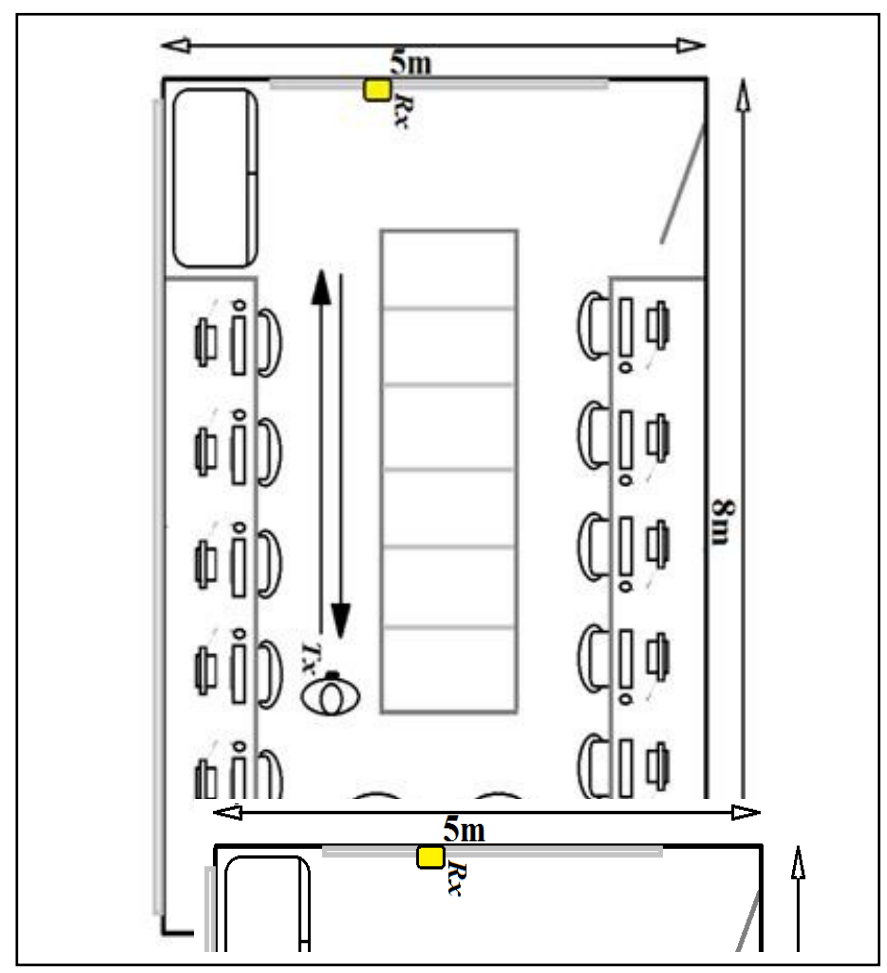

Fig. 1. Environment Layout.

Table 1 also summarizes the findings of mathematical modeling of the CDFs (Cumulative Distribution Function) for each trial. Analysis of this data shows that both the approach and retreat journeys for chest, shoulder and wrist-mounted antennas yield a Lognormal distribution in each case. It is also noted that the chest retreating scenario exhibits higher standard errors than all the others due to its higher range of received power values. The CDFs for received power (Fig. 2) further depict the statistical distribution of the power levels and show the chest retreating scenario as having the lowest overall power levels. Indeed the highest received power for the retreating chest arrangement is lower than all of the received power levels for every other scenario. These tests were conducted in a $40 \mathrm{~m}^{2}$ room with no other people in the environment; were such an UWB system deployed in a larger space or operated in the presence if other users (which would be expected considering the targeted application) the results would logically yield even lower received power and increased delay characteristics. From an application viewpoint this would result in data errors and service outages for the users. Based on these received power measurements it would questionable as to whether the chest would be a suitable choice of antenna location and in a larger environment one could expect the body-shadowing effects to be even more pronounced.

\section{B. Delay statistics}

For the isolated antenna, average $t_{\text {mean }}$ delay was $6.40 \mathrm{~ns}$ and average $t_{R M S}$ delay was $14.06 \mathrm{~ns}$. All trials where the transmitting body-antenna was approaching the receiver exhibit lower average $t_{\text {mean }}$ values than for the isolated antenna. The measurements for the shoulder-mounted bodyantenna retreating from the receiver had a slightly greater average $t_{\text {mean }}$ value compared to that of the isolated antenna, while the average $t_{\text {mean }}$ for the wrist-mounted retreating arrangement was less. However, the chest NLOS average $t_{\text {mean }}$ delay was considerably larger than the $t_{\text {mean }}$ for the isolated antenna (44.2 ns). This is due to the absence of a direct LOS ray during the journey. Thus all the tests except for the chest NLOS had average $t_{\text {mean }}$ values similar to the isolated values, attributable to the high degree of LOS geometry for a considerable portion of the journey, whereas the bodyshadowing configuration of the chest-mounted NLOS test requires the launched signal to utilize environmental reflectors and body diffraction to reach the receiver. Fig. 3 show $t_{\text {mean }}$ statistical distribution for the retreating chest-mounted antenna to have the largest range with a maximum recorded $t_{\text {mean }}$ value some five times that of the shoulder, ten times the wrist maximum mean delay and at least six times the maximum mean delay for all the LOS arrangements.

The general pattern of results for the average $t_{R M S}$ delay values are similar to those for the $t_{\text {mean }}$ delay, particularly the $t_{R M S}$ for the NLOS chest arrangement which was considerably greater than that for the isolated antenna. It is noted that the overall $t_{\text {mean }}$ and $t_{R M S}$ ranges were smallest for chest LOS and largest for chest NLOS arrangements, and that all $t_{R M S}$ ranges were greater than the isolated case except for the chest LOS, indicating the presence of the human body increases the average $t_{R M S}$ values for all trials except where wave directionality due to the body diminishes the effect. As with the $t_{\text {mean }}$ results, Fig. 4 shows the $t_{R M S}$ distribution for the retreating chest-mounted antenna to have the largest $t_{R M S}$ range with a maximum value 2.5 times that of the shoulder, three times the wrist's maximum RMS delay and at least 2.6 times the maximum RMS delay for all the LOS arrangements.

Analysis of the $t_{\text {mean }}$ and $t_{R M S}$ CDFs therefore confirm that the chest is not an advantageous choice of antenna location, as increased $t_{\text {mean }}$ and $t_{R M S}$ values signify a negative impact on the received signal quality and the quality of service as a whole.

Table 1 displays the best-fit statistical models for the delay measurements. All the CDFs for both $t_{\text {mean }}$ and $t_{R M S}$ delays are best described by the Lognormal distribution (each with different distribution parameters), except for the chest NLOS $t_{\text {mean }}$ and the chest NLOS $t_{R M S}$ which are most suitably described by the Weibull and Normal distributions, respectively. If the chest retreating scenario is likewise modeled using the Lognormal distribution the parameters are $\mu_{\mathrm{Est}}=-17.39, \mu_{\mathrm{Err}}=0.04, \sigma_{\mathrm{Est}}=0.69, \sigma_{\mathrm{Err}}=0.03$ for $t_{\text {mean }}$ and $\mu_{\mathrm{Est}}=-16.89, \mu_{\mathrm{Err}}=0.03, \sigma_{\mathrm{Est}}=0.52, \sigma_{\mathrm{Err}}=0.02$ for $t_{R M S}$. It is considered that for alternative geometries that would create strong NLOS arrangements, results for the shoulder and wristmounted antennas would be somewhat more comparable to the prominently different results of the NLOS chest configuration, such is the nature of the human body's shadowing effects at these frequencies. 

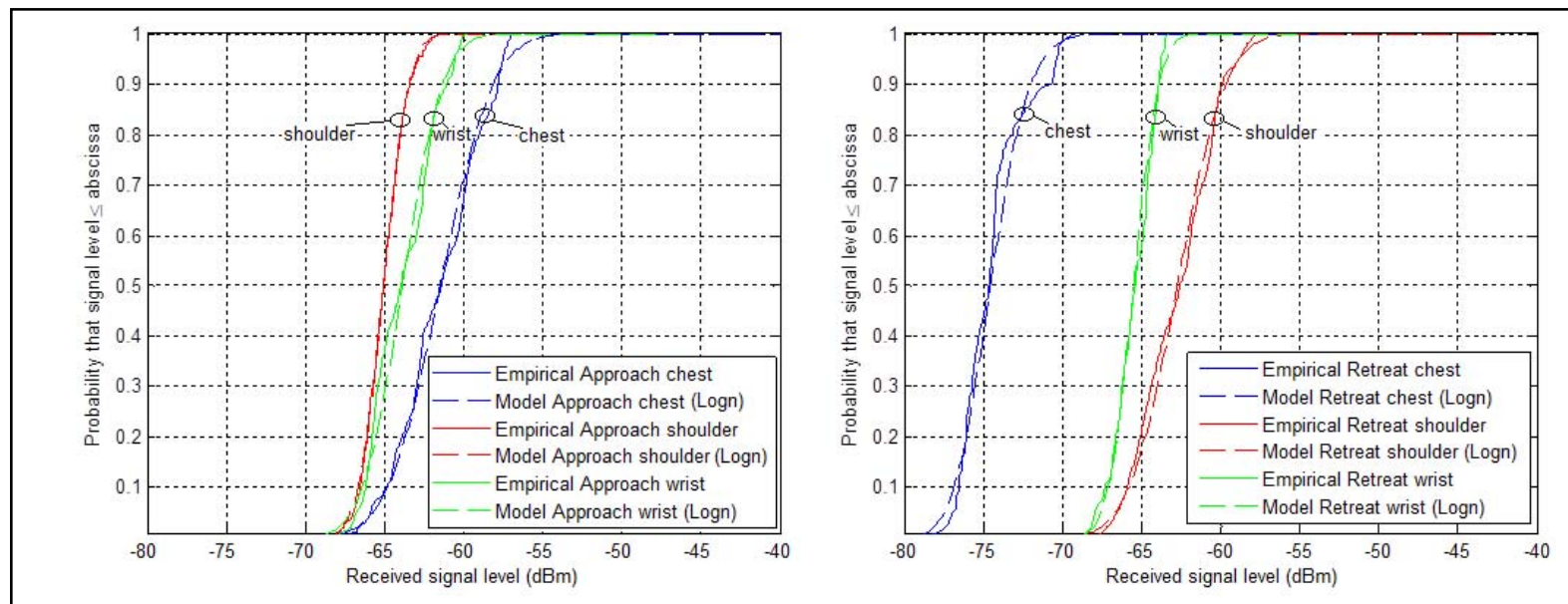

Fig. 2. Cumulative Distribution Function of Received power for Approaching and Retreating Journeys.

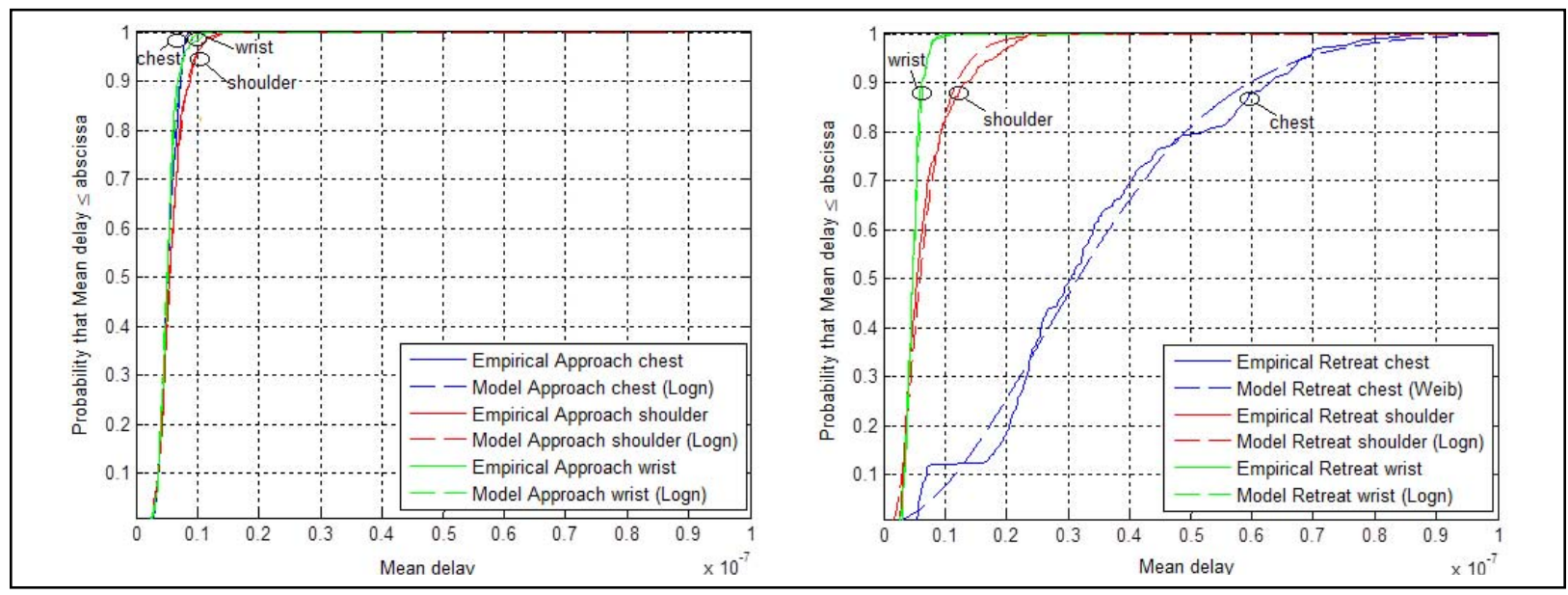

Fig. 3. Cumulative Distribution Function of Mean Delay $\left(t_{\text {mean }}\right)$ for Approaching and Retreating Journeys.

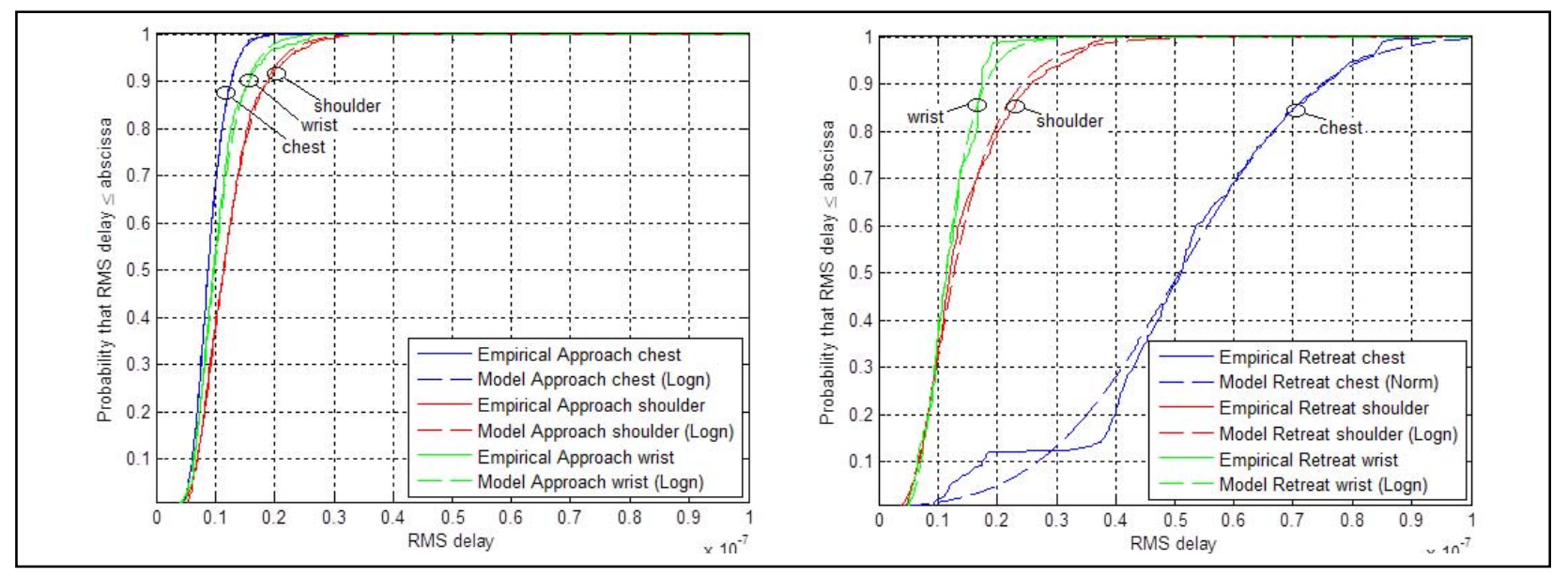

Fig. 4. Cumulative Distribution Function of RMS Delay $\left(t_{R M S}\right)$ for Approaching and Retreating Journeys. 
TABLE I. STATISTICAL PARAMETERS FOR RECEIVED POWER \& DELAY

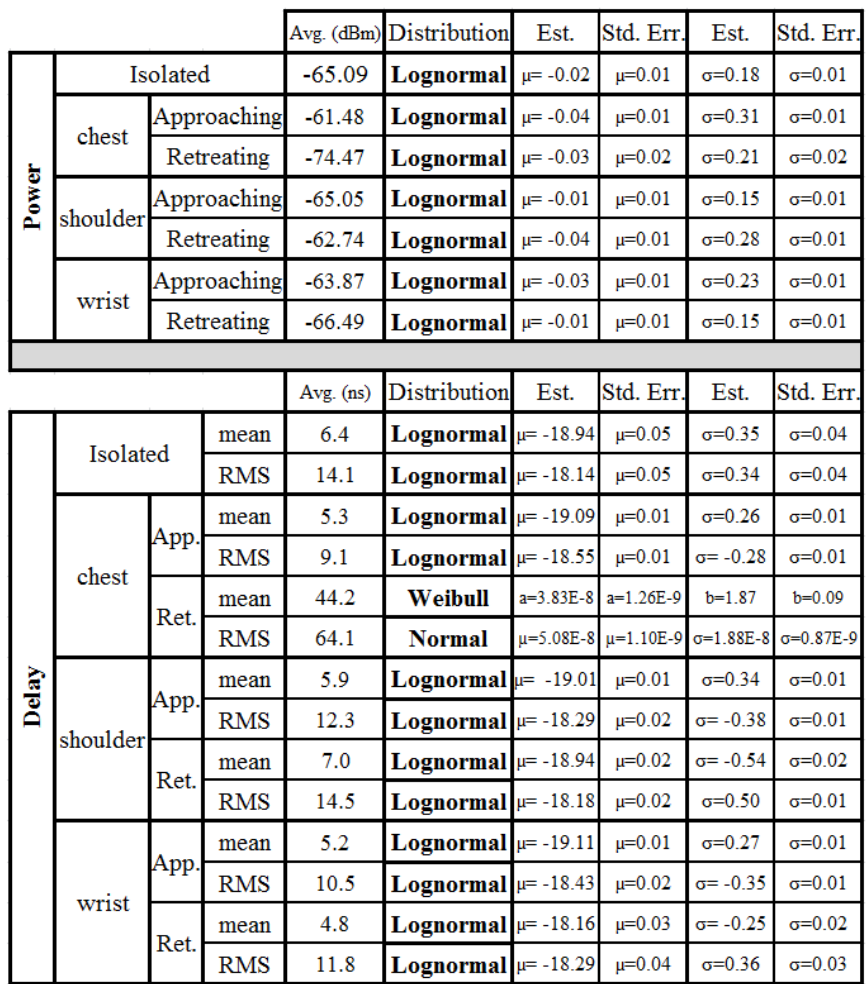

\section{CONCLUSIONS}

This paper has presented results from a measurement campaign to understand the effects of the antenna mounting position has on the quality of high-bandwidth off-body links in a contemporary learning environment. Considering the overall experience of the antenna mounting position for both approaching and retreating journeys the clear conclusion is that the chest is a poor choice of mounting position due to the high shadowing effects associated with the user's body when facing away from the base station receiver. Instead the wrist or shoulder are better candidates, with the wrist suggested as the marginally better choice for such an UWB link due to smaller signal delays and an average received power over both journeys on a par with that of the isolated antenna. Additionally, from a practical viewpoint it would be easier for a student to wear a watch-style transceiver than an armband or epaulette type device, which is supported by the increasing popularity of wrist-worn wearable computing devices [12].

This conclusion may not be applicable for a narrowband signal as such signals will suffer considerably from fading due to the wearer's wrist movement, thus it cannot be assumed that the presented results can simply be extrapolated to narrowband systems, as was investigated in [13]. UWB serves to mitigate these fading effects and is typically chosen for this reason, along with its characteristics of large channel capacity and low power spectral density. Future research is required to understand the effects that multiple transient and stationary pedestrians would have on the link characteristics. Further study is also required to understand the power and delay parameters measured for unrestricted movement within the environment.

\section{REFERENCES}

[1] Boticki, I.; Lung Hsiang Wong; Chee-Kit Looi, "Designing technology for content-independent collaborative mobile learning," IEEE Trans. Learning Technologies, vol.6, no.1, pp.14-24, 2013.

[2] Regueras, L.M.; Verdú, E.; Munoz, M.F.; Perez, M.A.; de Castro, J.P.; Verdú, M.J., "Effects of competitive e-learning tools on higher education students: A case study," IEEE Trans. Education, vol.52, no.2, pp.279-285, May 2009.

[3] Yue Suo, Naoki Miyata, Hiroki Morikawa, Toru Ishida, Yuanchun Shi, Open smart classroom: Extensible and scalable learning system in smart space using web service technology, IEEE Transactions on Knowledge and Data Engeering, Vol. 21, No. 6, pp. 814-828, June 2009.

[4] Alja'am, J.M.; Jaoua, A.M.; Alhazbi, S.; Hassan, M.; Elsaddik, A., “An assistive computerized system for children with moderate intellectual and learning disabilities," IEEE Global Engineering Education Conf. (EDUCON), pp.226-230, 4-6 April 2011.

[5] J. Hamzabegovic \& D. Kalpic, "A proposal for development of software to support specific learning difficulties," $12^{\text {th }}$ Intl. Conf. Telecommunications (ConTEL), pp.207-214, 26-28 June 2013.

[6] F.C.M.B. Oliveira, et. al., "The Haptic Deictic System-HDS: Bringing blind students to mainstream classrooms," IEEE Trans. Haptics, vol.5, no.2, pp.172-183, April-June 2012.

[7] M. Billinghurst \& A. Duenser, "Augmented Reality in the classroom", Computer, vol.45, no.7, pp.56-63, July 2012.

[8] Abbasi, Q.H.; Alomainy, A.; Yang Hao, "Recent development of Ultra Wideband body-centric wireless communications," IEEE Intl. Conf. Ultra-Wideband (ICUWB), vol.1, no., pp.1-4, 20-23 Sept. 2010.

[9] P.A. Catherwood \& W.G. Scanlon, "Measurement errors introduced by the use of co-axial cabling in the assessment of wearable antenna performance in off-body channels", European Conf. on Antennas and Propagation (EuCAP), Rome, pp. 3787-3791, 11-15 April 2011.

[10] Q.H. Abbasi, M.M. Khan, S. Liaqat, A. Alomainy, Y. Hao, "Ultra wideband off-body radio channel characterisation for different environments," $7^{\text {th }}$ Intl. Conf. Electrical \& Computer Engineering (ICECE), vol., no., pp.165-168, 20-22 December 2012.

[11] P.A. Catherwood, W.G. Scanlon, "Body-centric ultra-wideband multichannel characterisation and spatial diversity in the indoor environment," IET Microwaves, Antennas \& Propagation, vol. 7, no. 1, pp. 61-70, 2013.

[12] K. Malhi, S.C. Mukhopadhyay, J. Schnepper, M. Haefke, H. Ewald, "A Zigbee-based wearable physiological parameters monitoring system," IEEE Sensors Journal, vol. 12, no. 3, pp. 423-430, March 2012.

[13] A.J. Ali, W.G. Scanlon, S.L. Cotton, "Pedestrian effects in indoor UWB off-body communication channels," Loughborough Antennas and Propagation Conference (LAPC), vol., no., pp.57-60, 8-9 November 2010. 